\title{
CORRECTIONS
}

\section{Beethoven's deafness and his three styles}

In this Christmas article by Edoardo Saccenti and colleagues, we misspelt the name of the Isola String Quartet (BMJ

Cite this as: BMJ 2012;344:e512

2011;343:d7589, doi:10.1136/bmj.d7589). Additionally, the

๑ BMJ Publishing Group Ltd 2012 score we published was in fact a piano transcription of a late Beethoven string quartet (opus 130). 